University of Nebraska - Lincoln

DigitalCommons@University of Nebraska - Lincoln

\title{
Preservation and Erosion of Theropod Tracks in Eolian Deposits: Examples from the Middle Jurassic Entrada Sandstone, Utah,
} U.S.A.

Jesper Milán

University of Copenhagen

David B. Loope

University of Nebraska, Lincoln, dloope1@unl.edu

Follow this and additional works at: https://digitalcommons.unl.edu/geosciencefacpub

Part of the Earth Sciences Commons

Milán, Jesper and Loope, David B., "Preservation and Erosion of Theropod Tracks in Eolian Deposits: Examples from the Middle Jurassic Entrada Sandstone, Utah, U.S.A." (2007). Papers in the Earth and Atmospheric Sciences. 214.

https://digitalcommons.unl.edu/geosciencefacpub/214

This Article is brought to you for free and open access by the Earth and Atmospheric Sciences, Department of at DigitalCommons@University of Nebraska - Lincoln. It has been accepted for inclusion in Papers in the Earth and Atmospheric Sciences by an authorized administrator of DigitalCommons@University of Nebraska - Lincoln. 


\title{
Preservation and Erosion of Theropod Tracks in Eolian Deposits: Examples from the Middle Jurassic Entrada Sandstone, Utah, U.S.A.
}

\author{
Jesper Milàn and David B. Loope ${ }^{1}$ \\ Geological Institute, University of Copenhagen, Øster Voldgade 10, DK-1350 Copenhagen K, Denmark
}

(e-mail: milan@geol.ku.dk)

\begin{abstract}
A B S T R A C T
The Middle Jurassic Entrada Sandstone, exposed near the town of Escalante, southern Utah, consists of large-scale cross-bedded eolian deposits that are interbedded with horizontally laminated sand sheets and thin sets of eolian cross-strata, representing periods with a moister climate. The flat-bedded units contain numerous tracks and trackways from small to large-sized theropod dinosaurs. These tracks are today exposed in several distinct erosional states, allowing detailed studies of track and undertrack formation in eolian deposits. Tracks that originally were emplaced on sloping surfaces show, in their present-day erosional state, a morphology distinct from those originally emplaced on horizontal surfaces. Further, the range of eroded track morphologies can help identify badly eroded tracks from nonbiogenic structures in similar deposits.
\end{abstract}

No track begins or ends at the compression point. In other words, the track does not end at the floor, walls, horizons, and all the other visual places. Instead, the track is like the center of a concentric ring, a ring that ripples well beyond and under the existing track. (Tom Brown Jr., 1999)

\section{Introduction}

Well-preserved vertebrate tracks in the rock record can be an invaluable source of information about foot morphology, soft tissue distribution, and skin texture of the trackmakers' feet (Gatesy 2001). However, in most instances, the tracks are less than perfectly preserved, and sometimes they can be barely recognizable as tracks at all. Several factors influence the preservation of tracks. The consistency of the sediment in which the track is emplaced is the most critical factor; slight variations in the water content of the sediment cause dramatically different track morphologies, resulting in widely different fossil footprints from the same trackmaker (Brand 1996; Gatesy et al. 1999, 2005; Bromley 2001; Diedrich 2002; Gatesy 2003; Manning 2004; Milàn 2006; Milàn and Bromley 2006).

The sediment surface on which the animal leaves its tracks is termed the tracking surface sensu Fornós et al. (2002). The direct impression of the trackmaker's foot in the tracking surface is the true track 2006.

Manuscript received July 24, 2006; accepted October 10,

${ }^{1}$ Department of Geosciences, University of Nebraska, Lincoln, Nebraska 68588-0340, U.S.A.; e-mail: dloope1@unl.edu.
(Lockley 1991). When an animal walks, not only is the tracking surface deformed, but also the layers subjacent to the tracking surface are deformed. Experimental work with track formation shows that the weight of the trackmaker is transferred radially outward in the sediment around and below the foot (Allen 1989, 1997), forming a stacked succession of undertracks (sensu Lockley 1991). Normally, it is possible to distinguish undertracks from true tracks in that they are less detailed than true tracks and never preserve any fine anatomical details like skin impressions. Individual digit impressions become successively wider downward, and their amplitudes are diminished in the subjacent layers (Milàn and Bromley 2006). The sedimentary infilling of the track forms a natural cast of the track (Lockley 1991). In cases where the track is infilled gradually, the layers gradually drape the contours of the track and can, like an undertrack, be misinterpreted as a true track.

The aim of this study is to describe and interpret the many preservational variants of large theropod tracks from the Middle Jurassic Entrada Sandstone. The different erosional cuts through the true tracks, 


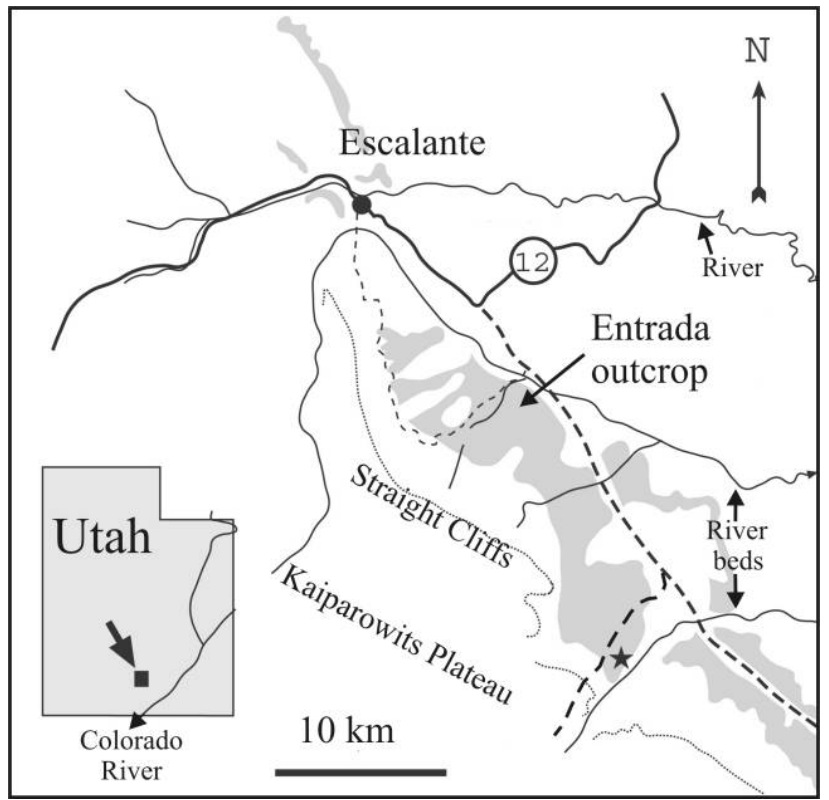

Figure 1. Location map. The studied outcrop of Entrada Sandstone, 20-Mile Wash locality, is located in the southern part of Utah, southeast of the town of Escalante. Star indicates the location of the studied locality. The dashed line indicates the unpaved Hole in the Rock Road branching southeast from Highway 12.

the undertracks, and the natural casts allow us to demonstrate the possibility of recognizing and utilizing badly eroded tracks.

\section{Geological Setting}

During the Middle Jurassic, present-day southern Utah was situated within the subtropics at a paleolatitude of about $18^{\circ} \mathrm{N}$ (Steiner 2003). The Escalante Member is the uppermost unit in the Middle Jurassic Entrada Sandstone (Thompson and Stokes 1970) and forms a prominent, 65-85-mthick, white to gray, cliff-forming unit. The studied outcrops of the Entrada Sandstone are located at the northeastern margin of the Kaiparowits Plateau, at the 20-Mile Wash locality, about $30 \mathrm{~km}$ southeast of the town of Escalante (fig. 1). Dinosaur tracks have previously been recorded from the 20Mile Wash locality (e.g., Foster et al. 2000; Breithaupt et al. 2004).

The large-scale compound crossbeds in the Entrada Sandstone have variable dip directions (fig. $2 A)$, suggesting a complex wind regime with more than one dominating wind direction. On the basis of the prevalence of simple sets of thick cross-strata with a persistently southeasterly dip in Lower Permian
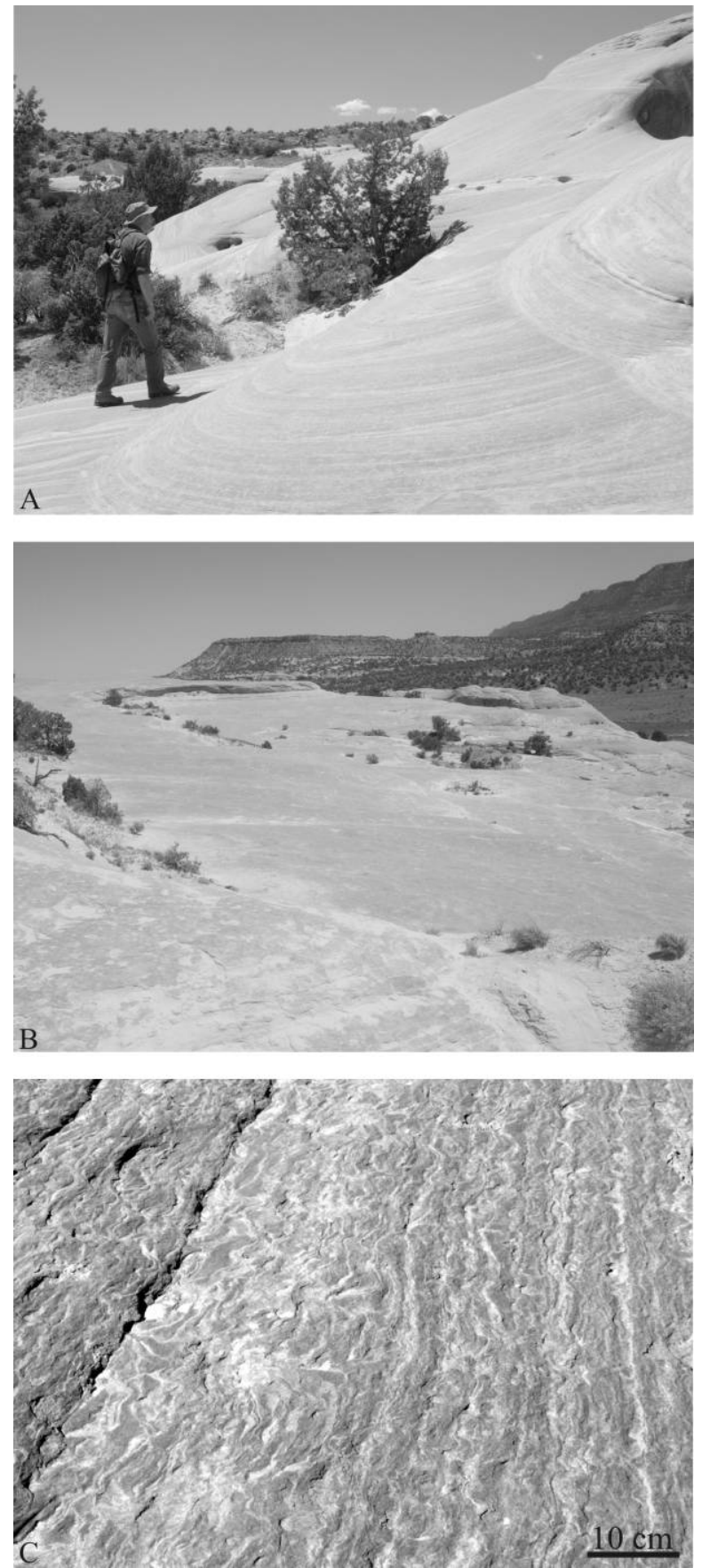

Figure 2. A, Entrada Sandstone exhibits large-scale cross-bedding with varying dip directions, resulting from seasonal shifts in wind regimes. $B$, Extensive surfaces of flat-bedded deposits are exposed at the 20-Mile Wash locality. The majority of the dinosaur tracks from the area are found on these surfaces. $C$, Flat-bedded strata in the Entrada Sandstone. Thin centimeter-thick sets of eolian cross-strata produced by small migrating dunes are interstratified with sand sheets deposited by wind ripples. The section shown slopes toward the right at approximately $30^{\circ}$. 
through Lower Jurassic eolian sandstones, Loope et al. (2004) suggested that tropical westerlies, blowing across the equator from the Northern Hemisphere during December to February, dominated in the region for about 100 millions years. During the Mesozoic, Pangaea was moving northward. The more variable dip directions observed in the Middle Jurassic Entrada Sandstone suggest that as Pangaea moved northward, summertime (June-August) windflow from the south played a more important role in the deposition of the Entrada Sandstone than in the Early Jurassic Navajo Sandstone.

The abundant large dinosaur tracks in the Escalante Member are preserved within flat-bedded eolian sand sheets and interbedded thin sets of eolian cross-strata (fig. 2B, 2C; fig. 3) that accumulated above a shallow water table (Loope and Simpson 1992). The tracks may have been formed during moist (pluvial) periods (Loope and Rowe 2003), when summer monsoon precipitation maintained a high water table in the dune field (fig. 3).

\section{Ichnofauna}

The flat-bedded deposits in the uppermost units of the Entrada Sandstone at the 20-Mile Wash locality contain a rich vertebrate ichnofauna dominated by tridactyl theropod footprints from 15 to $45 \mathrm{~cm}$ long. Dinosaur tracks are abundant in the Entrada-Summerville transition zone in Utah and can be traced in various outcrops for about $1,000 \mathrm{~km}^{2}$ as part of the "Moab Megatracksite" (Lockley and Hunt 1995; Lockley 1997). Most of the theropod tracks have well-defined digit impressions, and in the best-preserved cases, the impressions of the claws and the discrete vision of the digital pads are recognizable (fig. 4). A few of the tracks bear evidence of a semiplantigrade stance of the trackmaker, as a short metatarsus impression protrudes from the rear end of the tracks (fig. 4). The larger of the theropod tracks have been assigned to the ichnogenus Megalosauripus and the smaller ones to Therangospodus (Foster et al. 2000). A wide-gauge sauropod trackway assigned to Brontopodus is extraordinary in that it represents the earliest unequivocal evidence of sauropods from the western United States; furthermore, it has a prominent, sinuous drag mark from the tail in the midline of the trackway (Foster et al. 2000). In addition to the numerous dinosaur tracks, rhizoliths and insect burrows are also present in the flat-bedded strata. The largescale cross-strata of the Entrada Sandstone further contain 45-cm-diameter burrows from scratchdigging vertebrates (Loope 2006a) and sinuous, 25-

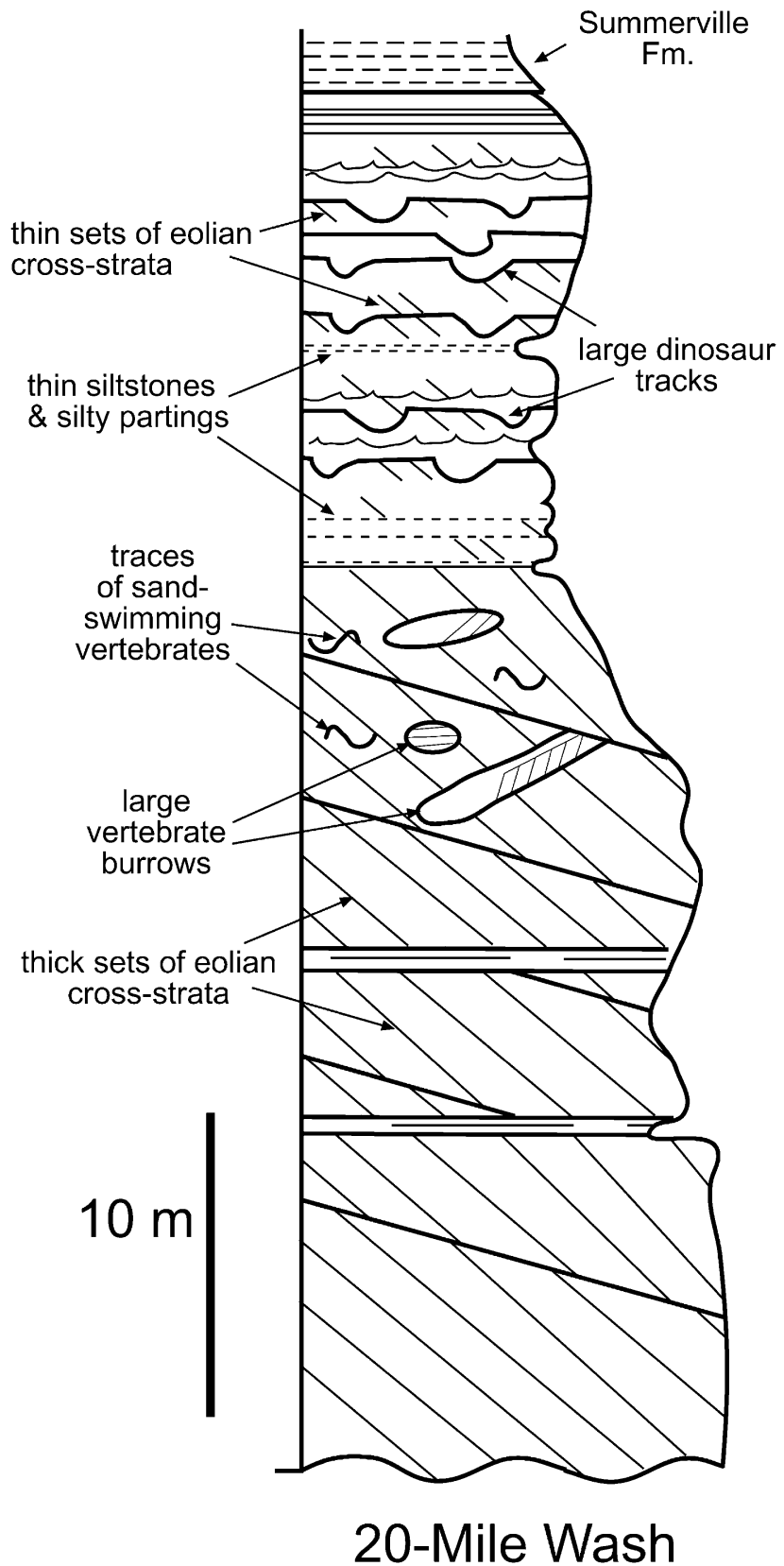

Figure 3. Stratigraphic section of Entrada Sandstone exposed at 20-Mile Wash. The large dinosaur tracks discussed in this article are restricted to the thin sets of eolian cross-strata in the upper part of the section, close to the Entrada-Summerville transition zone.

mm-diameter traces resembling those produced by sand-swimming vertebrates (Loope 2005).

\section{Preservational Styles}

The dinosaur tracks in the Entrada Sandstone are present in a wide range of preservational modes, 

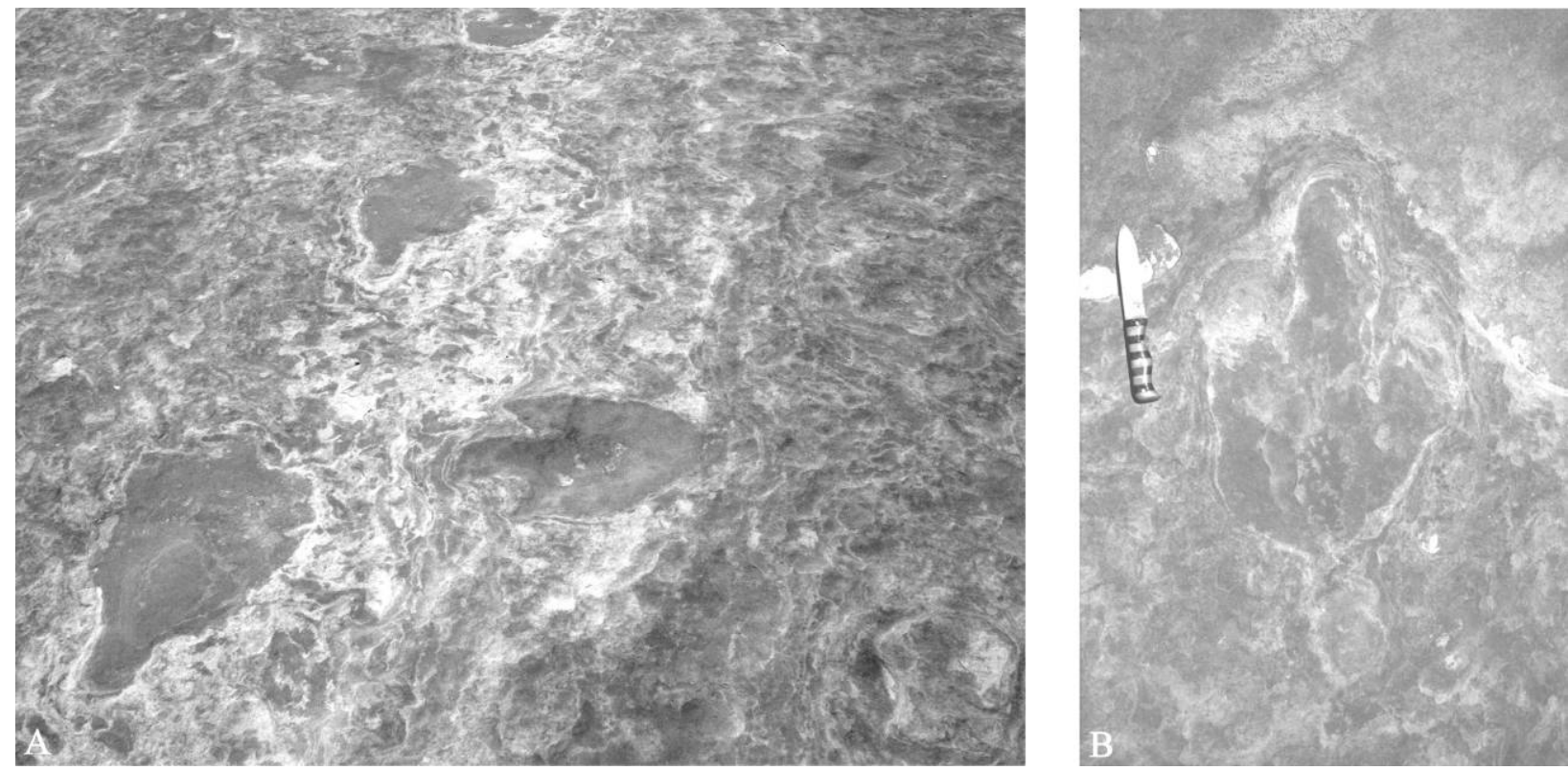

Figure 4. Large theropod tracks and trackways exposed in flat-bedded eolian strata near the top of the Entrada Sandstone. A, Trackway of large, approximately $40 \mathrm{~cm}$ long, posteriorly elongated theropod tracks. $B$, Theropod track (58 cm long) with partial metatarsus impression.

reflecting both differences in the gaits of the trackmakers and the paleoslope of the substrate. The present-day subaerial erosion of the sandstone outcrop has exposed the tracks in a variety of random erosional cuts oriented at different angles through both the true tracks and several subjacent horizons of undertracks.

Many of the tridactyl theropod tracks are preserved as true tracks, that is, the original tracks emplaced in the tracking surface by the dinosaurs. The true tracks have preserved impressions of many anatomical details of the foot, such as the number and arrangement of the digital pads in the individual digits of the foot and impressions of the claws (fig. 4A). Several of the larger theropod tracks show a posterior elongation of the track, resulting from a partial impression of the metatarsus during the stride (fig. 4B).

A number of the tracks and trackways are preserved with the original sedimentary infilling still in place. The sediments infilling the tracks are, in most cases, of a darker color than the sand constituting the original tracked surface. When eroded to this state, the darker coloring of the infilled sediments makes the tracks stand out clearly against the lighter-colored sediment of the original tracked surface (fig. 5A). Tracks preserved in this style are easily recognized as true tracks because they perfectly reflect the outline and shape of the theropod foot, in some cases even with the shape of the sharp claws preserved. Even the outlines of these tracks are well defined, but anatomical details like the size and distribution of digital pads cannot be observed because these are covered with the infilled sediment.

The sand sheets and the thin sets of cross-strata produced by small dunes (that make up the generally flat-bedded strata between the deposits of the large dunes) consist of numerous thin layers of finely laminated sand produced by migrating wind ripples. Not only did the dinosaurs deform the actual tracking surface as they emplaced their feet, but they also folded and ruptured the subjacent layers of sand to considerable depths below and around the actual track. This has caused the formation of well-developed undertracks subjacent to many of the observed tracks. The present-day erosion of the outcrop has, because of differences in hardness between the flat-bedded and large-scale cross-bedded deposits, favored the exposure of large surfaces of the flat-bedded deposits. Even though extensive surfaces of the flat-bedded deposits are exposed, the present-day surface does not represent a single bedding plane; instead, it represents an erosional surface in a package of thin sets of cross-strata and sandsheets eroded to different depths down through the layers.

The subsurface deformation of the thin sand lay- 

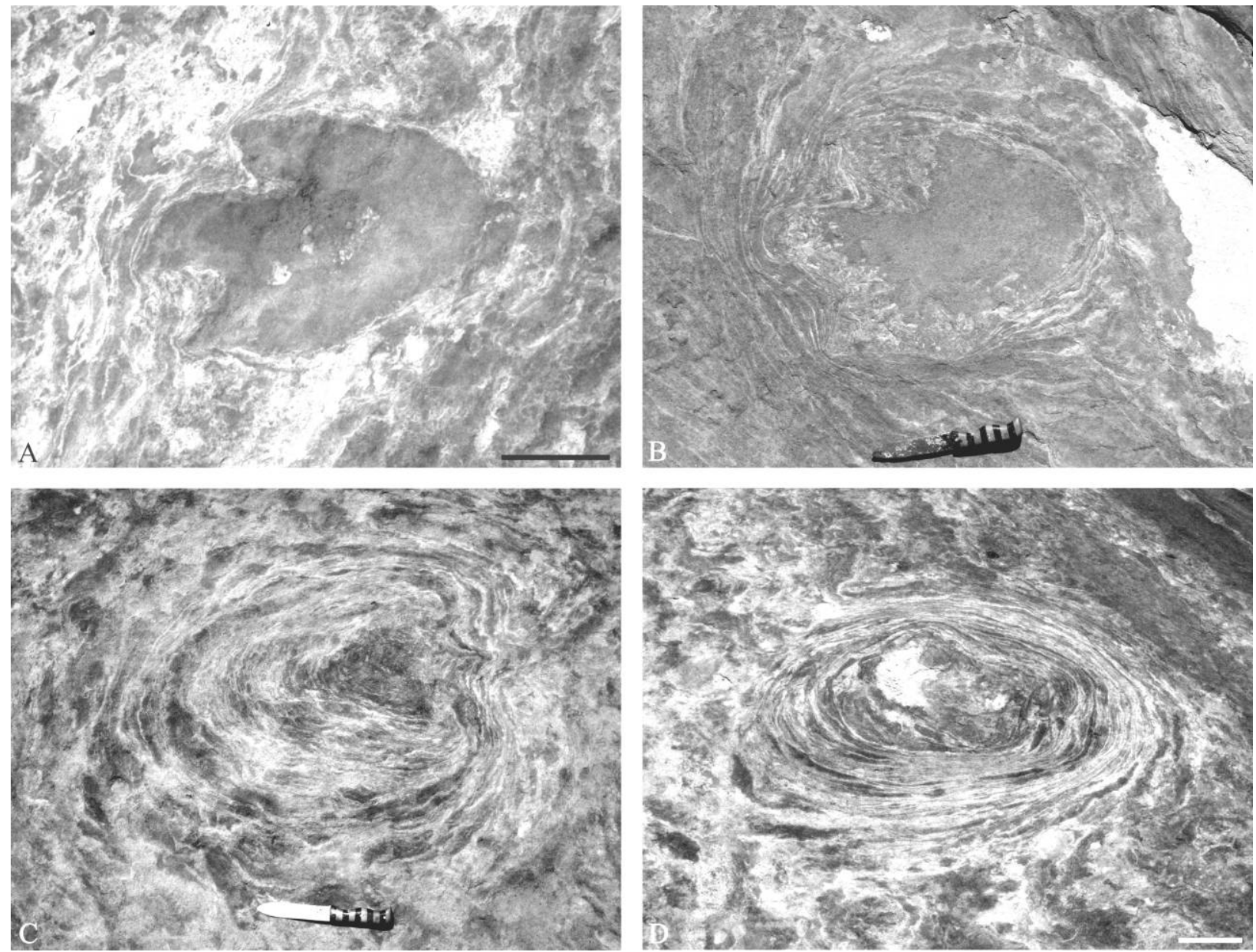

Figure 5. Preservational styles of theropod tracks from the Entrada Sandstone. A, True track infilled with sand of a darker color. The shape and outline of the track is well defined, with clear impressions from the claws. Scale bar $=10 \mathrm{~cm} . B$, True track with most of the sedimentary infilling eroded away. A series of concentric circles surrounding the track is present in the sediment. Knife handle is $10 \mathrm{~cm}$. $C$, True track is here almost eroded away; only the imprint of the middle digit is still present. Notice the well-developed concentric deformations around the track. Knife handle is $10 \mathrm{~cm}$. D, With the true track totally eroded away, the only evidence for the former presence of the track is the concentric circles developed by erosion of the undertracks. Scale bar $=10 \mathrm{~cm}$.

ers below the trackmaker's foot is clearly visible in the many different erosional states of the tracks. In some tracks, the sedimentary infilling is eroded away, partly exposing the bottom of the true track and features such as impressions of digital pads. Interestingly, a curious feature occurs in the sediment around tracks eroded to this depth: a series of apparently concentric circles are present around the track up to $20 \mathrm{~cm}$ away from the true track (fig. $5 B$ ). Close to the perimeter of the track, the curves follow the shape of the tracks; that is, the divisions between the digits are reflected in the concentric deformations as well. Tracks eroded to a depth where almost the whole true track is eroded away show a distinct morphology because only the im- pression of the middle digit, which was most deeply impressed into the substrate, is preserved. A large set of concentric circles of deformation originating from the tip of the impression of the middle digit forms a 70-cm-long zone of deformed layers on the surface (fig. $5 C$ ). In some instances, the original tracked surface has been eroded to such an extent that the true track is completely eroded away. Surrounding the former position of the true track, a prominent series of concentric circles of deformed layers extends for $20-30 \mathrm{~cm}$ outward from the position of the true track, forming an elliptical zone of deformation approximately $70 \mathrm{~cm}$ in greatest diameter (fig. 5D).

Large areas of the exposed flat-bedded deposits 
are eroded to the same level today. This allows the same trackway to be followed for long distances in the same erosional state. Tracks still containing the darker-colored sedimentary infilling can be found as long consecutive trackways, apparently because the infilling is slightly more resistant to erosion than the surrounding sediment (fig. 6A). Another long trackway exists in a more advanced erosional state where the true tracks have been almost completely eroded. Erosion has exposed the subjacent deformed layers, and the trackway consists of barely recognizable true tracks, each with a welldeveloped set of concentric deformations extending outward (fig. 6B). The most curious trackway found at the locality was an extensive trackway where all the true tracks are eroded totally away, but the trackway is still clearly visible and could without a problem be traced for about $40 \mathrm{~m}$, because each track is now represented by an eroded undertrack consisting of a broad zone of concentric circles at the present-day surface (fig. 6C).

One particular trackway consisting of four tracks is preserved on an erosional slope where the flatbedded deposits have been differentially eroded down about $20 \mathrm{~cm}$ over a 4-m interval, thereby cutting through several individual thin sand sheets. This has caused each consecutive track in the trackway to be present in a more eroded state than the previous one (fig. 7). The first track is preserved with the darker-colored infilling still in place and has further preserved an elongated metatarsus impression. The second track is well defined, has preserved impressions of the individual digits and claws, and is partly infilled by darker sediment. The third track is present only as an undertrack and consists of a series of concentric circles in the sediment. The fourth track is only vaguely recognizable as a faint zone of concentric deformations in
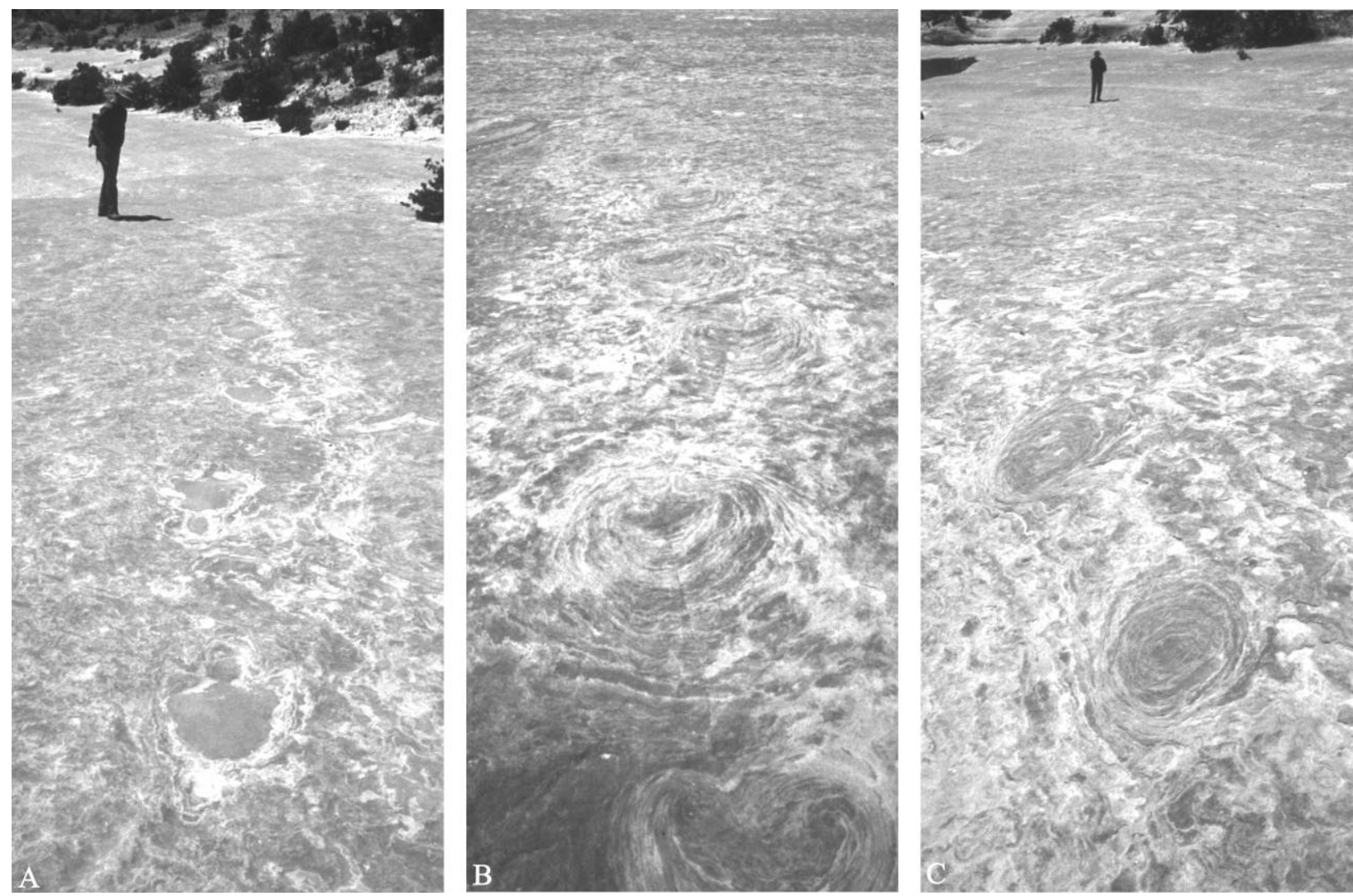

Figure 6. Theropod trackways in different preservation states. A, Long trackway preserved with each track still filled with the darker-colored sedimentary infilling. $B$, Trackway where each track is partly eroded away. Notice the prominent concentric circles of deformation surrounding the vestiges of the true tracks. $C$, Trackway where the true tracks are totally eroded away. Only the erosional cut through the concentric circles of the undertracks reveals the former presence of the trackway. This "undertrackway" can be traced all the way to the person in the background of the picture. 
the sediment. By comparing the morphology trackby-track down through the different eroded states, it is evident that the tracks were originally impressed to about $10 \mathrm{~cm}$ depth (as indicated by the thickness of the infilled sediment) and that the undertracks disturbed layers for a further $10 \mathrm{~cm}$ below the tracks (fig. 7C).

The above described tracks all originate from horizontally deposited sand sheet deposits; however, a number of localities reflect areas with sloping paleorelief. Eroded tracks found on these sloping parts of the eolian deposits show peculiar morphology in that they show a unidirectional deformation of the sediments down the paleoslope of the deposit, forming a fan of deformation originating from the remains of the true track (fig. 8).

In areas with more extensive present-day erosion of the flat-bedded deposits, such as on the steeply sloping edges of the outcrop, several tracks can be found as oblique cuts through both the true tracks and undertracks. The best cuts through the tracks were observed on an erosional surface that slopes approximately $30^{\circ}$. From these sections, the timing and formation of true tracks, undertracks, and sedimentary infilling can be reconstructed. The layer constituting the original tracking surface has been
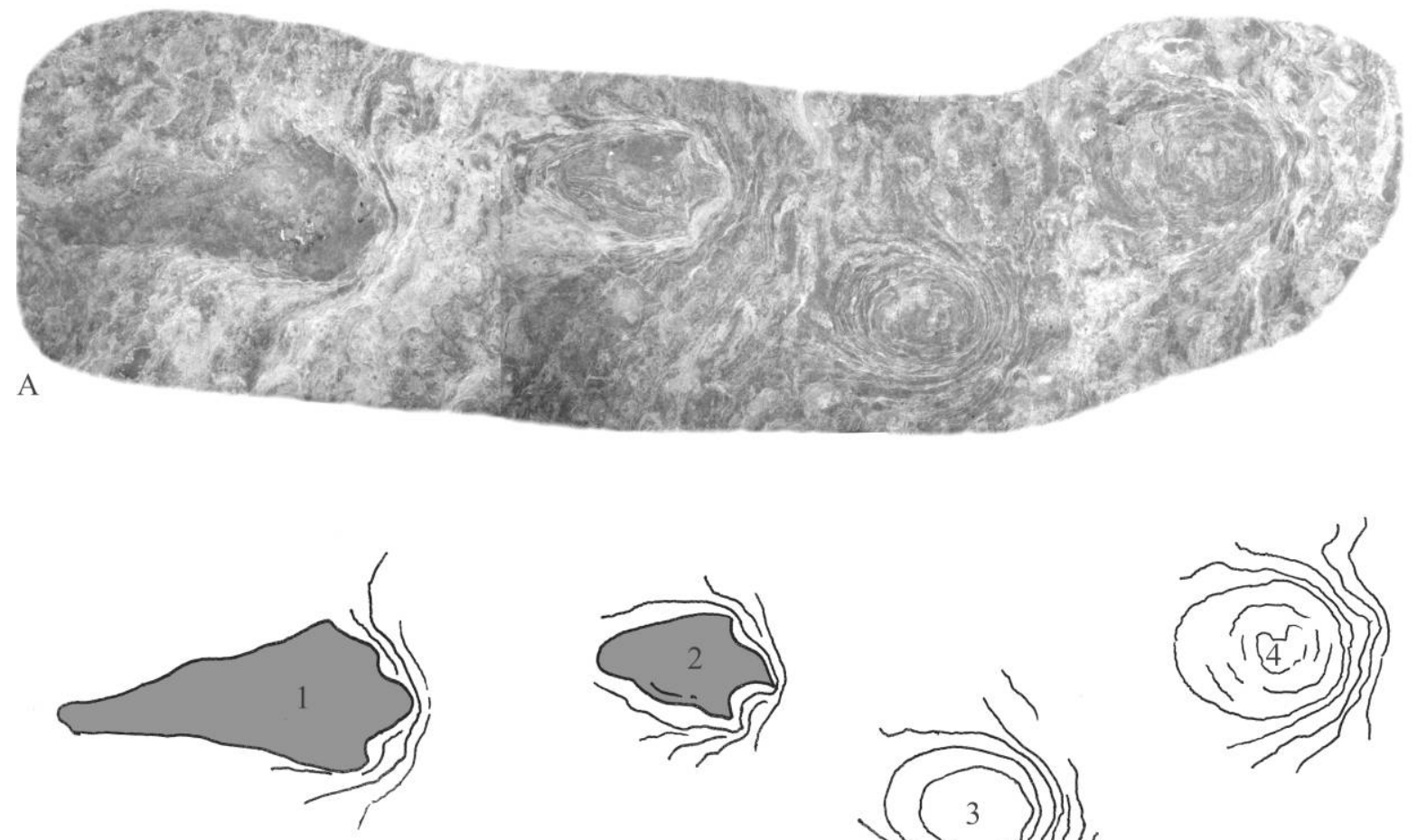

B
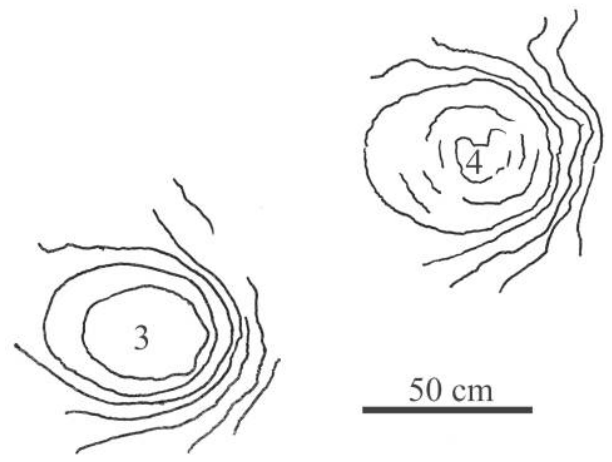

$50 \mathrm{~cm}$

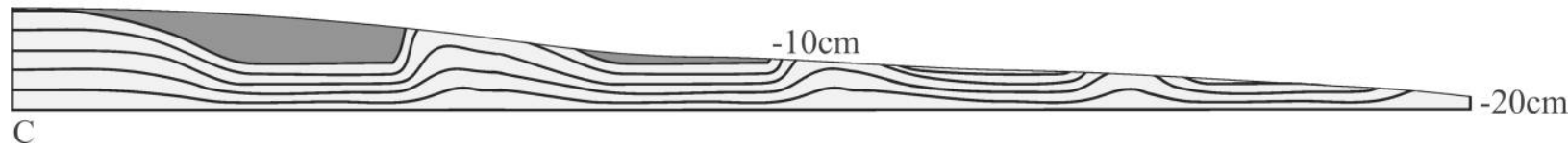

Figure 7. Trackway segment found on a sloping erosional surface. $A$, Trackway consists of four tracks, each representing a different erosional layer. $B$, Sketch of the trackway showing the different morphology of the tracks. Track 1 has an elongated metatarsus impression and is infilled with darker-colored sediment. Track 2 is well defined with impressions of individual digits and claws and is partly infilled with darker-colored sediment. Notice the deformations of the layers surrounding the track. Tracks 3 and 4 are undertracks and are preserved only as concentric circles of deformation in the sediment. $C$, Hypothetical vertical section through the sloping surface with the tracks. The different sections through the tracks demonstrate that the tracks disturb a zone of 20 -cm thickness in the thin-bedded eolian deposits. 


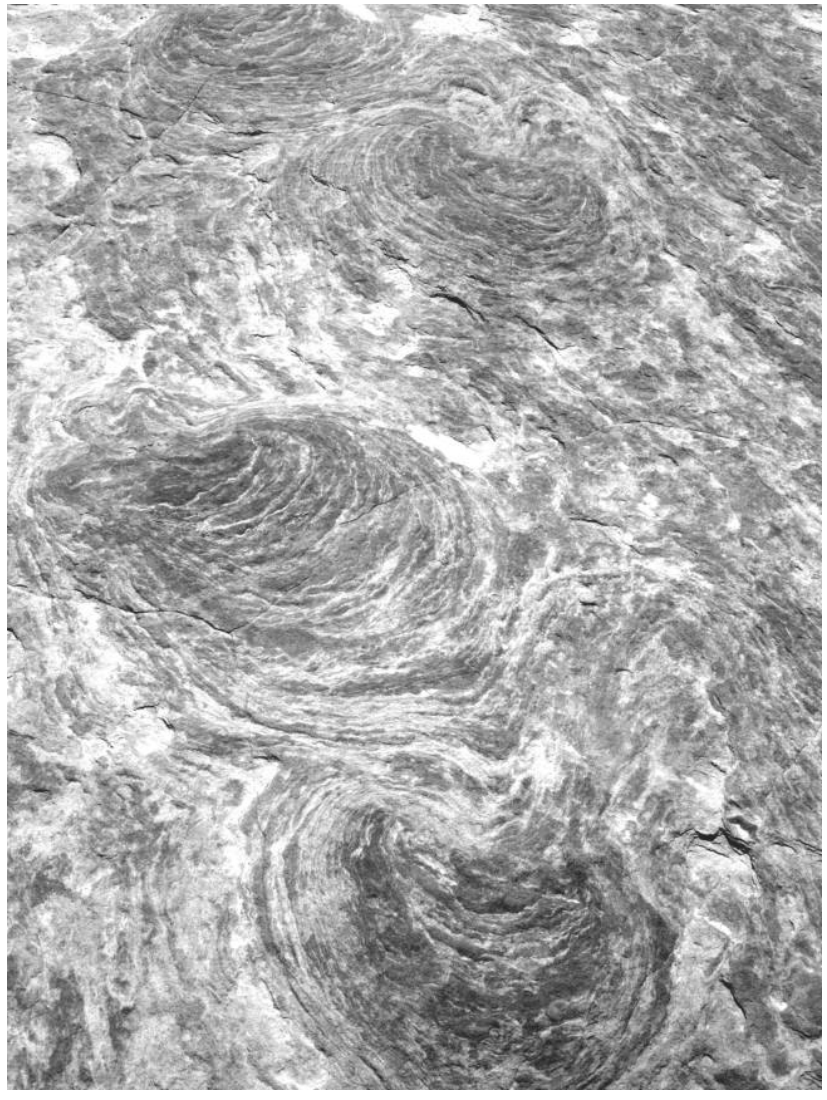

Figure 8. Erosional cuts through tracks emplaced on a sloping tracking surface. When the tracks were formed, the weight of the trackmaker displaced a rim of sand on the downslope side of the trackmaker's foot. In the present-day erosional cut, the rim of displaced sand is visible as a system of eccentric rings of deformation originating from the downslope side of the true track and spreading outward, indicating the original downslope side of the track.

cut by the foot, and the layers have been bent downward, forming steep trackwalls. Undertracks are formed in the subjacent layers, radiating downward and outward below the track, forming a stack of successive wider and shallower undertracks subjacent to the true track (fig. 9). The sediment infilling the track is of a darker color than the sediment of the tracking surface and, when viewed in the present section through the track, appears as a subrectangular, structureless lens of darker sediment surrounded by the deformed, layered sediments.

\section{Preservational Models}

The wide range of erosional states of the theropod tracks from the flat-bedded deposits allows us to present the following scenarios for their formation and preservation. The preservational variants of the tracks emplaced on the horizontally laminated deposits (fig. 5) can all be explained by different degrees of erosion through a track emplaced and buried under the following circumstances. (1) The track is emplaced in a package of thin, horizontally laminated sand sheets (fig. 10A). (2) The weight of the trackmaker displaces the sediments surrounding the foot in a radial pattern, forming a rim of displaced material around the track. A stacked succession of successively shallower and broader undertracks is formed along the subjacent sand horizons (fig. 10B). (3) A darker-colored layer of sand covers the depositional surface (fig. 10C). (4) Present-day erosion through the layers exposes the tracks and the surrounding deformation structures, with the track and the sedimentary infilling still in place surrounded by concentric rings created by the erosion of the surrounding ring of displaced sediment (fig. 10D). If eroded to a deeper level, all of the true track and the sedimentary infilling are destroyed, and the only evidence of the track is a shallow, undefined undertrack in the middle and the concentric rings from the displaced sediment surrounding the track (fig. 10E).

The formation and curious mode of preservation of the tracks from the sloping parts of the eolian deposits can be explained by the following scenario. (1) The trackmaker emplaces the foot vertically on

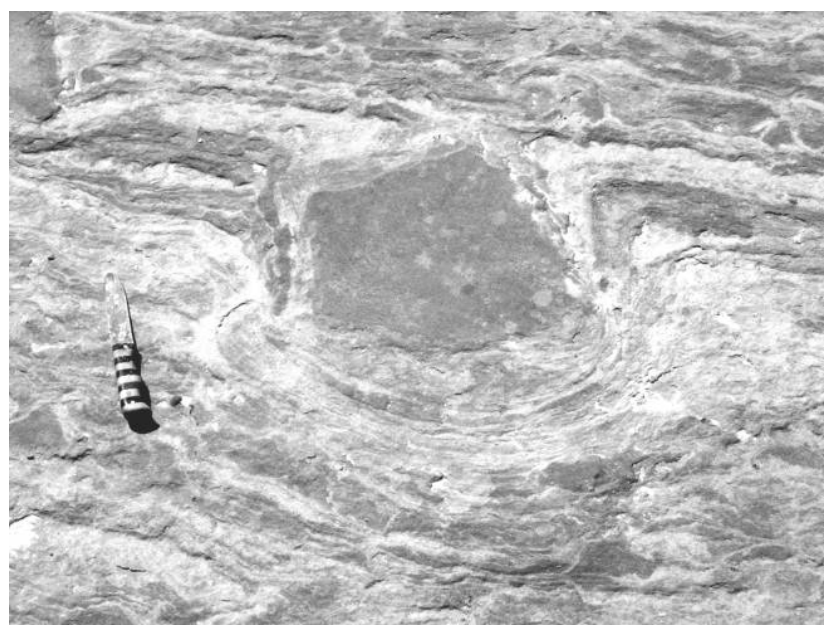

Figure 9. Erosional cut through a track infilled with sediment of a darker color than the sediment of the tracking surface. The view was generated by an approximately $30^{\circ}$ cut through the layers. Notice how the coarsergrained, darker infilling of the tracks appears as a subrectangular, structureless unit surrounded by deformed, laminated eolian deposit. Knife handle is $10 \mathrm{~cm}$ long. 


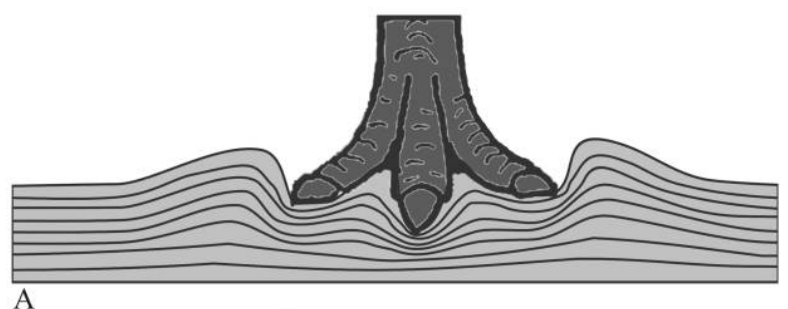

A

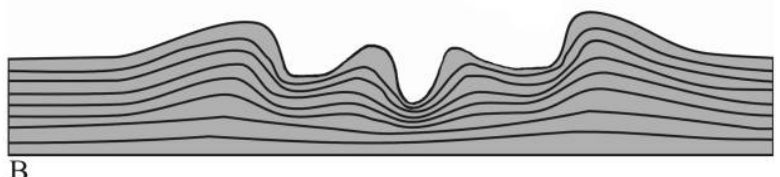

B
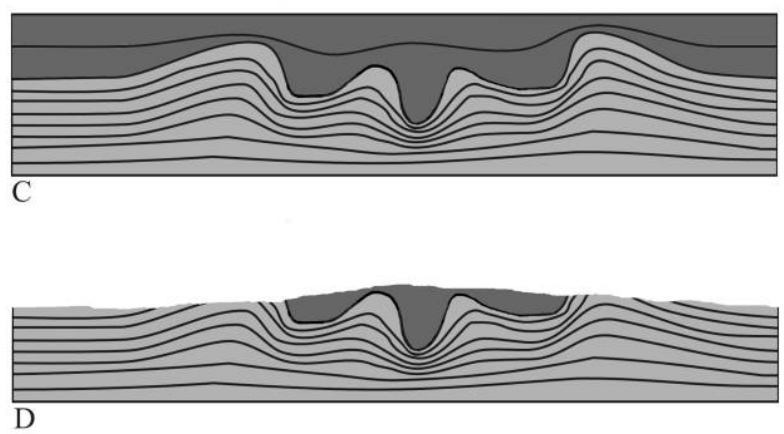

$\mathrm{D}$

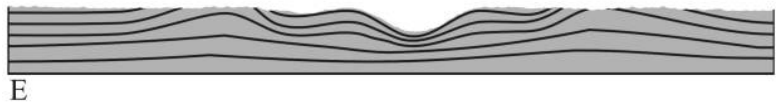

Figure 10. Schematic model for the formation of the various erosional forms of the tracks found on the horizontally deposited eolian deposits. $A$, Foot of the trackmaker is emplaced on the laminated deposits. $B$, Weight of the trackmaker displaces the sandsheet laminae outward around the foot, creating a circular marginal ridge of displaced material. Undertracks are formed along the subjacent horizons, down to at least $10 \mathrm{~cm}$ below the track (cf. fig. 7). C, Track is filled with darker-colored sediment. $D$, Present-day erosion has exposed the track with the sedimentary infilling still in place. The erosion of the surrounding marginal ring of displaced material creates the pattern of concentric rings around the tracks (cf. fig. 5B). E, With the true track totally eroded away, the only hint of the track is now the shallow undertrack and the concentric rings of the eroded marginal ridge of displaced material (cf. fig. 5C, 5D).

the sloping surface (fig. 11A). (2) The sediment displaced by the trackmakers foot forms a rim on the downslope side of the footprint (contrary to the condition on the horizontal surface where the sediment is uniformly displaced radially around the track). Undertracks are formed in the layers subjacent to the true track, becoming successively shallower and wider downward. The sideways deformation of the track due to the sloping of the tracking surface is also present in the undertracks (fig. 11B). (3) The tracking surface becomes covered by slightly darker-colored sediment, draping the contours of the track and adjacent deformation structures (fig. 11C). (4) Exposed to the present-day erosion, the track appears as a series of eccentric rings of deformation, originating in the eroded remains of the infilling of the true track (fig. 11D).

\section{Discussion}

The tracks and undertracks of large theropods found in the Entrada Sandstone at the studied locality come in a wide range of morphologies, mainly as a result of present-day erosion that has exposed the track-bearing surfaces at different depths. It is reasonable to believe that the welldefined tridactyl footprints with preserved impressions of claws and individual digital pads are indeed true tracks (fig. 4), since experimental work with track and undertrack formation has shown that these anatomical details disappear in undertracks, while the general shape of the foot remains recognizable to a considerable depth (Manning 2004; Milàn and Bromley 2006).

The impression of the metatarsus in some of the larger theropod tracks is evidence of a semiplantigrade stance adopted by the trackmaker. Plantigrade theropod tracks are occasionally encountered as ichnofossils and can be the result of an actual plantigrade walk of the trackmaker (Kuban 1989). But partial impressions of the metatarsus can also occur if the trackmaker walks in soft sediment and the foot sinks to a considerable depth (Gatesy et al. 1999).

The tracks from the flat-bedded deposits appear to be emplaced in relatively damp sand, which allowed extensive deformation to occur in the layers below and around the track. The laminae in and subjacent to the theropod tracks from the Entrada Sandstone are commonly fractured (brecciated; figs. $4 A, 5 C)$, which is a typical type of deformation occurring in moist sand. Similar tracks from the Early Jurassic Navajo Sandstone are interpreted as wet season tracks, in contrast to dry season tracks that preserve evidence of dry eolian grainflows triggered by the dinosaurs' feet (Loope 2006b). Experiments with track formation in different horizontal substrates, including dry sand, damp sand, and wet sand, demonstrate that totally dry sand is a bad medium to preserve true tracks because the track- 


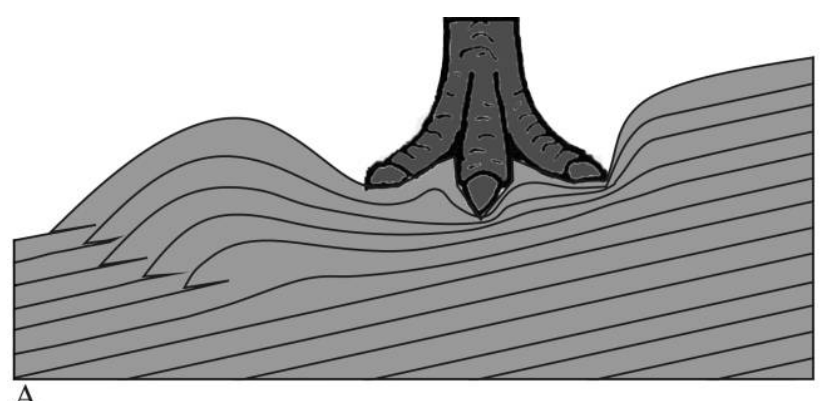

A
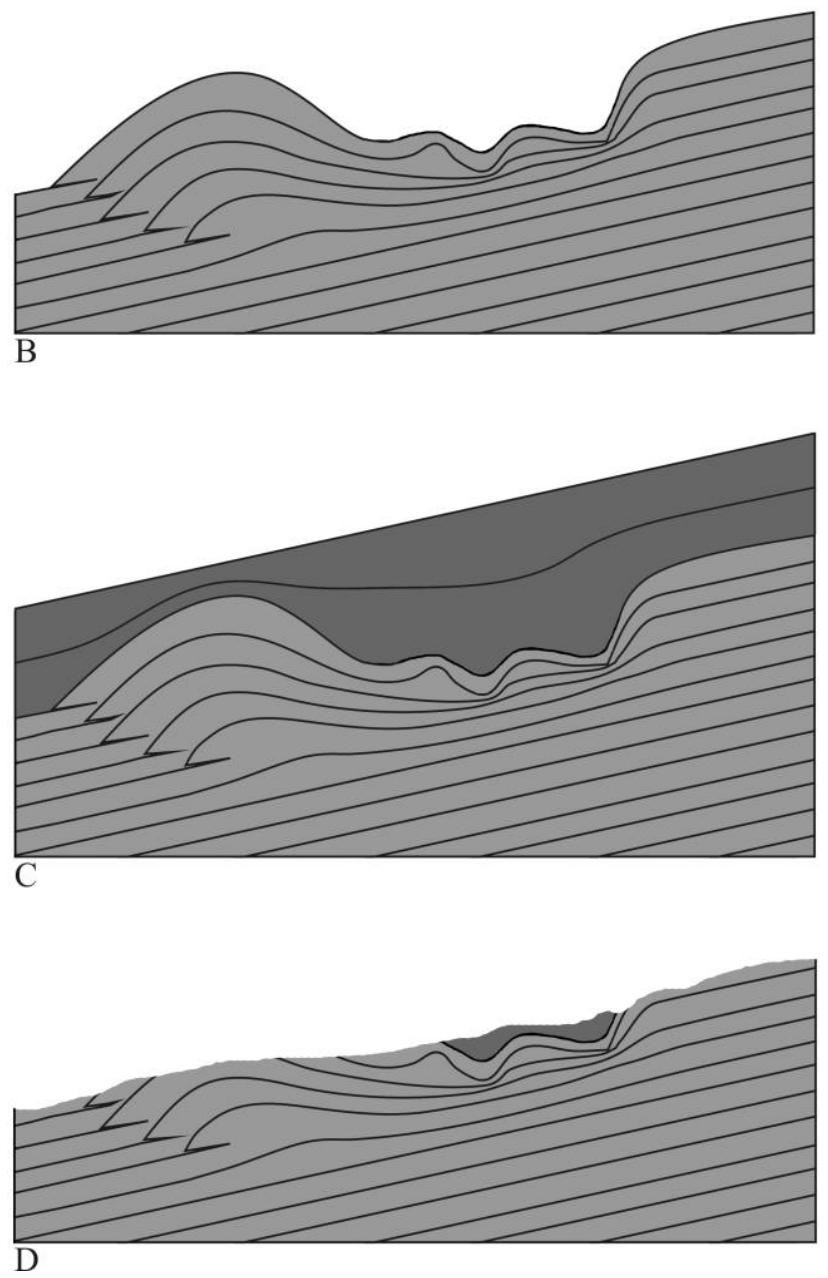

Figure 11. Schematic model for the formation of the tracks found on the sloping parts of the eolian deposits. $A$, Trackmaker emplaces the foot vertically on the sloping surface. $B$, Trackmaker's foot creates a rim of displaced material on the downslope part of the track. Undertracks are formed in the layers subjacent to the foot. $C$, Surface and track are covered with sediment of a darker color. $D$, Present-day erosion of the surface has exposed the tracks at various levels, with the most prominent feature being the pattern of elliptical concentric rings created by the erosion through the rim of displaced material from the downslope side of the track (cf. fig. 8). walls immediately collapse, leaving only the vague outline of the tracks left with little potential for fossilization. Tracks emplaced in damp sand, however, are well defined, with clear impressions of anatomical details such as digital pads, claws, and even, in some cases, skin texture. Wet sand tends to flow together and collapse some time after withdrawal of the foot, making it a bad medium for track preservation (Milàn 2006).

Even in cases where the true tracks are totally eroded away, the general trackway pattern is still recognizable because the present erosional cut through the undertracks makes the vestiges of the individual tracks appear as a series of concentric ring structures in the sand (fig. 6C). However, even though the general pattern of the trackway is still recognizable, the information about the trackmaker that can be extracted from the trackway is limited. Where the true tracks are fully eroded away and only the undertracks are present, it is still possible to calculate the trackway parameters such as stride length, pace length, and pace angulation. In this case, the measurements must be taken from a fixed point in each track, such as the middle of the deformation structures. On the other hand, attempts to estimate the progression speed from trackways consisting of undertracks should be avoided, since one of the parameters needed to calculate the progression speed is the hip height, which is a multiple of the trackmaker's foot length (Alexander 1976; Thulborn 1990). Extreme caution should be taken when trying to estimate the foot length of an animal from trackways where only the undertracks are preserved, since the apparent dimensions of the track become larger downward at each subjacent layer because the weight of the trackmaker's foot is transferred radially outward into the sediment (Allen 1997; Milàn and Bromley 2006). Any application of the (apparently larger) foot length derived from an undertrack will give a higher estimated hip height and thus a relatively shorter stride length, resulting in a slower speed estimate.

\section{Conclusions}

The Middle Jurassic Entrada Sandstone contains numerous dinosaur tracks, dominated by medium to large-sized theropod tracks. The tracks appear in eolian sand sheets interbedded with thin sets of eolian cross-strata that lie above the deposits of large-scale dunes. Present-day erosion has exposed the tracks in a wide range of preservational states, ranging from well preserved, with the sedimentary infilling of the true tracks still in place, to deeply eroded, with the 
only evidence of the animal's passage being the circular structures created by erosion through the undertracks. The study of the different eroded states of the tracks and trackways shows that each of the large theropod tracks has generated a zone of disturbance up to $20 \mathrm{~cm}$ wide in the thin-bedded deposits, including the true track, the sedimentary infilling, and the extensive set of undertracks.

The many morphological variants of the theropod tracks found in the Entrada Sandstone due to extensive undertrack formation and subsequent erosion to different levels demonstrate that great care should be taken when describing fossil footprints that have been exposed to subaerial erosion, because the shape, dimensions, and general appearance of the footprint become seriously altered by erosion. Such erosion could take place on the modern outcrop, as in the present case, or in the ancient setting before final burial.
When studying eolian sediments, special attention should be paid to horizons with deformation structures. The wide range of erosional states exhibited by the studied tracks, ranging from welldefined, easily recognizable tracks to tracks eroded to a nearly unrecognizable state, demonstrate that what might look like random deformation structures in the sand layers might very well be the eroded remains of vertebrate tracks.

\section{A C K N O W L E D G M E N T S}

The research of J. Milàn is financed by a PhD grant from the Faculty of Natural Science, University of Copenhagen. D. B. Loope's work was funded by a grant from the National Science Foundation (EAR02-07893). We are grateful to M. G. Lockley and R. Rogers, who provided critical and constructive reviews of the manuscript.

\section{R E F E R E N C E S C I T E D}

Alexander, R. M. 1976. Estimates of speeds of dinosaurs. Nature 261:129-130.

Allen, J. R. L. 1989. Fossil vertebrate tracks and indenter mechanics. J. Geol. Soc. Lond. 146:600-602.

- 1997. Subfossil mammalian tracks (Flandrian) in the Severen Estuary, S. W. Britain: mechanics of formation, preservation and distribution. Philos. Trans. R. Soc. B 352:481-518.

Brand, L. R. 1996. Variations in salamander trackways resulting from substrate differences. J. Paleontol. 70: 1004-1010.

Breithaupt, B. H.; Matthews, N. A.; and Noble, T. A. 2004. An integrated approach to three-dimensional data collection at dinosaur tracksites in the Rocky Mountain West. Ichnos 11:11-26.

Bromley, R. G. 2001. Tetrapod tracks deeply set in unsuitable substrates: recent musk oxen in fluid earth (East Greenland) and Pleistocene caprines in Aeolian sand (Mallorca). Bull. Geol. Soc. Den. 48:209-215.

Brown, T., Jr. 1999. The science and art of tracking. New York, Berkley, 219 p.

Diedrich, C. 2002. Vertebrate track bed stratigraphy at new megatrack sites in the Upper Wellenkalk Member and orbicularis Member (Muschelkalk, Middle Triassic) in carbonate tidal flat environments of the western Germanic Basin. Palaeogeogr. Palaeoclimatol. Palaeoecol. 183:185-208.

Fornós, J. J.; Bromley, R. G.; Clemmensen, L. B.; and Rodriguez-Perea, A. 2002. Tracks and trackways of Myotragus balearicus Bate (Artiodactyla, Caprinae) in Pleistocene aeolianites from Mallorca (Balearic Islands, western Mediterranean). Palaeogeogr. Palaeoclimatol. Palaeoecol. 180:277-313.

Foster, J. R.; Hamblin, A. H.; and Lockley, M. G. 2000. The oldest evidence of a sauropod dinosaur in the western United States and other important vertebrate trackways from Grand Staircase-Escalante National Monument, Utah. Ichnos 7:169-181.

Gatesy, S. M. 2001. Skin impressions of Triassic theropods as records of foot movement. Bull. Mus. Comp. Zool. 156:137-149.

- 2003. Direct and indirect track features: what sediment did a dinosaur touch? Ichnos 10:91-98.

Gatesy, S. M.; Middleton, M. K.; Jenkins, F. A.; and Shubin, N. H. 1999. Three-dimensional preservation of foot movements in Triassic theropod dinosaurs. Nature 399:141-144.

Gatesy, S. M.; Shubin, N. H.; and Jenkins, F. A. 2005. Anaglyph stereo imagining of dinosaur track morphology and microtopography. Palaeontol. Electronica 8:10A.

Kuban, G. J. 1989. Elongate dinosaur tracks. In Gillette, D. G., and Lockley, M. G., eds. Dinosaur tracks and traces. Cambridge, Cambridge University Press, p. 5772.

Lockley, M. 1991. Tracking dinosaurs. Cambridge, Cambridge University Press, 238 p.

- 1997. The paleoecological and paleoenviromental utility of dinosaur tracks. In Farlow, J. O., and BrettSurman, M. K., eds. The complete dinosaur. Bloomington, Indiana University Press, p. 554-578.

Lockley, M., and Hunt, A. P. 1995. Dinosaur tracks and other fossil footprint of the Western United States. New York, Columbia University Press, 338 p.

Loope, D. B. 2005. Abundant traces of sand-swimming vertebrates preserved high on the slopes of giant Jurassic dunes. Geol. Soc. Am. Abstr. Program 7:339.

- 2006a. Burrows dug by large vertebrates into rainmoistened, Middle Jurassic sand dunes. J. Geol. 114: $753-762$. 
2006b. Dry-season tracks in dinosaur-triggered grainflows. Palaios 21:132-142.

Loope, D. B., and Rowe, C. M. 2003. Long-lived pluvial episodes during deposition of the Navajo Sandstone. J. Geol. 111:223-232.

Loope, D. B., and Simpson, E. L. 1992. Significance of thin sets of eolian cross-strata. J. Sediment. Res. 62: 849-859.

Loope, D. B.; Steiner, M. B.; Rowe, C. M.; and Lancaster, N. 2004. Tropical westerlies over Pangeaean sand seas. Sedimentology 51:315-322.

Manning, P. 2004. A new approach to the analysis and interpretation of tracks: examples from the Dinosauria. In McIlroy, D., ed. The application of ichnology to palaeoenviromental and stratigraphic analysis. Geol. Soc. Lond. Spec. Publ. 228:93-123.

Milàn, J. 2006. Variations in the morphology of emu (Dro- maius novaehollandiae) tracks, reflecting differences in walking pattern and substrate consistency: ichnotaxonomical implications. Palaeontology 49:405-420.

Milàn, J., and Bromley, R. G. 2006. True tracks, undertracks and eroded tracks, experimental work with tetrapod tracks in laboratory and field. Palaeogeogr. Palaeoclimatol. Palaeoecol. 231:253-264.

Steiner, M. B. 2003. A cratonic Middle Jurassic paleopole: Callovian-Oxfordian stillstand (J-2 cusp), rotation of the Colorado Plateau, and Jurassic North American apparent polar wander. Tectonics 22:1020.

Thompson, A. E., and Stokes, W. L. 1970. Stratigraphy of the San Rafael Group, southwest and south central Utah. Utah Geol. Mineral. Surv. Bull. 87:1-53.

Thulborn, T. 1990. Dinosaur tracks. London, Chapman \& Hall, $410 \mathrm{p}$. 